\title{
Research on the Course Teaching Reform of Management Information System in Big Data Environment
}

\author{
Dahui $\mathrm{Hu}^{1, \mathrm{a}}$, Zhiguo $\mathrm{Du}^{1, \mathrm{~b}^{*}}$ \\ ${ }^{1}$ Business school of Southwest University, China \\ ahudahui@hotmail.com, du_zhiguo@hotmail.com \\ * The Corresponding Author
}

Keywords: Big data; Teaching reform; Management information system; Information processing

\begin{abstract}
Management information system is one of the core courses of management specialty, and it is a new frontier subject. The content of the course is closely related to the modern enterprise management systems, management concepts and management methods. However, college students are not so interested in this course for lack of experience of business exercise. In order to augment the appeal of this course, the author puts forward a case teaching method by which practical cases of modern enterprise management combine with the teaching content in classroom process. Simultaneously, students can simulate every link of modern enterprise management in the experimental courses and they can design solutions and solve related problems. With this case teaching method, students' enthusiasm in learning has been greatly improved, students' grasp of classroom content is firm and students' ability to solve problems is further promoted. In a word, the case teaching method has achieved the intended purpose of teaching in this course.
\end{abstract}

\section{Introduction}

With the continuous promotion of informatization, the data scale is massive, the amount of data showing a hitherto unknown world's explosive growth, with its vast amount of data, data types, data generation speed, accurate and great value and play an important role in various fields. The era of big data has brought great changes to the analysis and application of the data, not only reflected in the massive data processing requirements, but also requires innovation in the mining of data processing tools, the value of the need to have enough knowledge and ability, and talent to meet the development of the times.

With the development of big data technology, the teaching of management information system course, which aims at information processing and decision-making management, is facing great challenges. The traditional teaching mode has not been able to keep pace with the development of the times and the needs of the society. As an interdisciplinary science with multiple disciplines, management information system mainly involves many fields, such as computer technology, network technology, economics and management. It is the ability that talents must have in the age of big data. How to keep up with the development of big data, cloud computing and the Internet of things is the key issue for teaching reform of management information system. Driven by the era of big data, the establishment of a comprehensive teaching and practice mode that accords with the requirements of the times is the inevitable trend of teaching reform of management information system.

\section{Inevitability of Teaching Reform}

Big data processing mainly analyzes and classifies the massive data stored in a distributed database to meet most of the conventional analysis requirements. The data sources of big data are multidimensional and stereoscopic, providing more comprehensive, more visual angle and better material for the discovered rules. Compared with traditional data processing, big data processing emphasizes the authenticity and timeliness of data mining, finding association, anomaly, trend and value, and can derive more personalized and detailed value-added services. The big data age broadens 
the scope of market demand and calls for high level and complex innovative talents with modern advanced information technology and management ability.

According to the relevant departments, it is expected that in the next 5 years, the demand for data processing related personnel in the government, media and enterprises will reach 1 million. However, at present all aspects of personnel training does not conform to the requirements, needs of the era of big data talent market changes, market demand between industries and enterprises requirements focus change, different requirements of talent ability and skills have a certain difference. The requirements for talents in the era of big data and pay more attention to whether talents have rich practical experience and skilled operating skills and talents, compared the specialty of information management and information system and the traditional management personnel, the biggest difference lies in the stronger ability of information processing, strong computer related technology. The professional training mainly from universities, colleges and universities for the training of personnel training is not limited to the theoretical knowledge, also carried out a series of training for practical ability, knowledge and practice of effective integration, in order to cultivate qualified new age level talents to meet the needs of talent market, the mainstream development direction of talents the development of the times.

The main reasons for the urgent reform in the course teaching of the management information system are as follows:

\section{Information and Large Amount of Data Processing}

The course of the management information system needs to be combined with the actual case of the enterprise, especially the case of the top 500 enterprises in the world. It is necessary to improve the teaching material system, enrich the teaching resources, optimize the teaching organization, and follow the frontiers. Collecting cases of management information system at home and abroad, forming multi-level, multi form and characteristic resource repository, and collecting these data by using big data technology, and learning and analyzing autonomously, and self-improvement. The database of management information system curriculum resources has the characteristics of continuity, rapid increase of data volume and involved aspects. The conventional data processing method is no longer applicable. In the course construction and research, we must add big data technology to solve the problem of massive data processing.

\section{Real-time Data Update}

In the course of management information system, the real time and continuity of the case, the data need to be updated in real time and real-time collection. Only by using big data processing technology can the data be guaranteed to be continuous and up-to-date.

\section{Teaching Materials cannot adapt to Different Specialties}

The management information system course in different majors should have different teaching requirements, for the management of professional students, the key is to let the students for information technology an important role in the management of enterprises have a clear understanding, let students understand and grasp the structure of management information system, basic function method and perfect management information system. For information management and information system majors, the emphasis of teaching should be placed on practical operation ability, so that students can master the ability of developing simple information management system. Therefore, different majors have different teaching requirements and emphasis. Although the existing textbooks will be applied to the cover of textbooks, the content of textbooks is basically the same.

\section{Separation of Theoretical Teaching and Practice}

In the teaching method, the course of management information system is still in the traditional mode of teaching teachers, classroom instruction and rarely into case practice activities, fewer cases of the development process of management information system complete, students understand and master the theoretical knowledge of management information system has a significant negative impact. 


\section{Knowledge Structure of the Teacher Team is Single}

Most of the teachers are directly engaged in the teaching work after graduation, and lack the practical ability to apply knowledge and practice. Under the rapid development of management information system theory and technology, we cannot grasp the cutting-edge technology, there are limitations in teaching, and affect the teaching effect of management information system course.

\section{Concrete Measures for Teaching Reform}

Specialty of information management and information system in the training program, should be based on the design of information management and information system analysis and design, and Realization of management information system as the focus, combined with big data thinking, cultivating talents with the ability of information management, system development ability, data processing ability. Combined with the characteristics of the industry, the author puts forward the specialty of information management and information system course system aimed at training with three aspects of theory and practice and application of the quality of personnel, through the analysis of big data application technology field direction, identify the professional employment advantage, for the enterprise to provide qualified personnel.

To achieve the above effect, it must be implemented in the following aspects:

\section{Select a Case with Big Data Features}

In the process of selection of teaching cases in the selected case, pay attention to diversity, innovative, practical and comprehensive, carefully selected case of big data, the Internet, networking development requirements, broaden the students' knowledge, so that students will be good to learn the theory of knowledge is closely linked with the actual, specific application better to guide the students to think of the management information system, improve the students' ability to analyze and solve practical problems, increase the students in big data, the Internet of things under the background of the fine management, precision analysis and real-time decision-making ability training.

\section{Design Cases that Conform to the Characteristics of Big Data}

In order to achieve the goal of teaching, we mainly design 3 different types of teaching cases: analysis case, design case and comprehensive case. The analytical case is a successful complex information system, which allows students to have a more profound perceptual knowledge of the management information system under the background of big data. The design case is to give a specific demand for a complex information system serving an industry field, so that students can carry out complex information system planning, demand analysis and system modeling according to the theories, methods and technologies that have been grasped. A comprehensive case is to cooperate with big data company to select a complex information system based on mobile Internet and Internet of things under the background of big data. It emphasizes students' understanding and understanding of big data analysis and processing, implementation and application of Internet of things.

\section{Improve the Practical Conditions}

The establishment of an open laboratory and professional teachers to guide the students' professional practice. Signing an internship agreement with enterprises, setting up relevant practice bases, hiring managers to give lectures for students, enabling students to understand the actual working situation of enterprises and understand the actual needs of enterprises.

\section{Diversification of Practical Teaching Mode}

The practice teaching activities should not only pay attention to the experiment of the curriculum, but also change the traditional practice. The practice teaching should follow the theory teaching and improve the degree of connection between the courses. Students are encouraged to participate in social practice and production practice, so that students can feel the actual situation of the enterprise and understand the actual needs of the enterprise. The school can introduce the actual project, make the students participate in the whole project process, feel the project process, and train the students' ability to solve the actual problems. 


\section{Establish an Internship Base}

To establish the corresponding practice base, students can practice in depth, improve the effectiveness of students' practice and the utilization rate of practice bases. It is also possible to select some students to go deep into business practice, not only to motivate students to participate in practice, but also to gain more practical experience.

\section{Conclusion}

Under the big data environment, higher requirements and goals for information management and information system professional training are put forward. The contents of specialty construction of management information system should reflect the characteristics of big data era and the direction of enterprise talent demand. Specialty of information management and information system need to be big data talent to implement, carry out systematic curriculum construction of information management and information system, combined with the industry and the needs of the times, clear information management professional training objectives, optimize the curriculum structure, curriculum of the times and practicality, in order to make the students become talents.

Personnel training is an important task for colleges and universities, teaching reform of management information system under the background of big data, through case analysis, design of case teaching method, implementation of heuristic teaching, research teaching and individualized teaching combination, is conducive to the cultivation of information management and information system of students, to cultivate high-quality applications talents, talents to provide a strong support for the rapid development of social economy in the era of big data.

\section{Acknowledgement}

In this paper, the author was sponsored by "Teaching reform project of Southwestern University" (project number: 2017JY048).

\section{References}

[1] X.M. Zhou: Reform and Discussion on Case Teaching in Management Information System of Economic Management Major in the Context of Big Data, Journal of Hunan University of Commerce, Vol.23(2016)No.1,p.115.(In Chinese)

[2] S.H. Tian and T.L. Liu: Research on Information Management and Information System Comprehensive Practice System under the Background of Big Data, Journal of Heilongjiang College of Education, Vol.35 (2016) No.9, p.37. (In Chinese)

[3] Y. Gao: The Construction of the Course Group in the Information Management Specialty under the Background of Big data, Computer Education, Vol.9 (2014) No.24, p.8.

[4] X.G. Yu: Research on International Teaching of Management Information System Course under Big Data Environment, Software Guide, Vol.15 (2016) No.5, p.216.

[5] J. Wang: Research on the Course Teaching Reform of Management Information System in the Era of Big Data, China Management Informationization, Vol.17(2014)No.16,p.15.(In Chinese)

[6] W.J. Zeng and Q. Fang: Research on Applied Curriculum Reform of Information Management and Information System under Big Data, China Computer and Communication, Vol.15(2017)No.2,p.231.(In Chinese) 